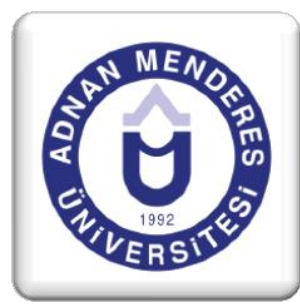

\title{
Yapısökümcülük Neyi Söküyor: \\ Jacques Derrida'yı Anlamak
}

\section{What Does Deconstructionism \\ Deconstruct? : Understanding Jacques Derrida}

\author{
Serhan GÜL ${ }^{1}$
}

\section{Özet}

Derrida, dilbilimi ve felsefe arasında kurduğu köprüyle, felsefenin iletişimsel bir faaliyet olarak yeniden kurgulanması kadar, post-yapısalcı ile tarihsel olan arasındaki ilişkiyi onararak, düşünsel dünyada büyük bir çığır açar. Dilbilimi ve fonoloji üzerinden yürüttüğü tartışma, bizi dilin, tüm kullanımıyla tarihsel ve değer-bezeli bir muhtevası olduğuna ve yine bu değerlerin aydınlanma sonrası pozitivist okul içerisinde ete kemiğe bürünen nesnellik iddialarıla çevrelenmiş bir yapı üzerine inşa edildiğini açılar. Ona göre, sökülmesi gereken bu yapı, bilim ve felsefe etkinliklerimizin sınırlarından, toplumsal kodların üretimi ve yeniden üretiminine kadar yaygın olan logos'tur. Bu temel mantık saikinin sökümü, ancak onun kuşattığı tüm kodlamaların sökülmesiyle ve alternatif bir dil düzleminde mümkün olabilecektir. Bu da yine Derrida'da günümüzde imkansız bir noktayı ifade eder. Derrida, aporetic okuma yoluyla, görece anlam bütünlerinden ve logosundan sökülmüş metinleri okumaya girişerek aslında daha geniş ölçekli bir etki alanı yaratır: Toplumsal anlamlandırmaların sorgulanarak, şüpheci ve özneci postmodern felsefeyi canlandırarak, kendisi de dahil tüm batı düşünce dünyasının mantık silsilesini koparır. Bu açıdan yapısökümcülük aynı anda hem imkansız hem de muvaffak bir akım olarak tanımlanabilecektir.

Anahtar Kelimeler: Derrida, yapısökümcülük, logos, gramatoloji, fenomenoloji

\footnotetext{
${ }^{1}$ Araş. Gör., Adnan Menderes Üniversitesi Söke İşletme Fakültesi Kamu Yönetimi Bölümü, serhan.gul@adu.edu.tr, Aydın
} 


\begin{abstract}
Derrida, bridging between lingustics and philosophy, opens up new horizons in the intellectual, not only by repairing post-modernist and historicist schools, but also by leading to a reconciliation of philosophy as a communicative action. His debate over linguistics and phonology, drags us to think that language has a deeply value-laden and historical framework and also that these values are constructed upon a structure that is remarked with the claims of being objective which is aroused after the enlightenment positivist school. According to him, this structure, which is ought to be "deconstructed", is the logos, which surrounds science and philosophy and production and reproduction of social codes and norms. The deconstruction of this basic element of logic is only possible by dismantling of all codes innate in language and by an alternative language. Which again for Derrida, corresponds to an impossibility. Derrida, following an aporetic reading on relatively disassembled from sets of meaning and logos, creates a larger effect: By questioning social meanings, by reanimating sceptical and "subjectist" philosophy, ruptures the logical structure of all western thought, including himself. In this respect, deconstructionism can be described as a school both impossible and victorious, at the same time.
\end{abstract}

Keywords: Derrida, deconstructionism, logos, grammatology, phenomenology

\title{
1. Giriş
}

Derrida, 20 yüzyılda düşünsel tartışmalara önemli katkılar yapmış ve postmodern teoride en başta gelen isimlerden biri olarak yerini almıştır. Bu çalışmada, imkan olduğu ölçüde Derrida ve temsil ettiği yapısökümcülük yaklaşımının ana hatları ortaya konacak ve üzerine kısaca tartışma imkanları yakalanmaya çalışılacaktır. Burada aslında tartışması zor ve hatta anlamsız olan tam da teorinin geçerliliğidir. Derrida'nın şaşmaz şüpheciliği aslında kendi iddialarını en baştan çürüterek ikircikli bir durum ortaya koyar. Buna göre, Derrida'nın sunduğu hakikat de pekala çürütülebilecektir. Bu nedenle, Derrida'yı savunmak kadar eleştirmek de zor bir uğraştır. 
Joshua Kates, genellikle olumlayıcı bir açıdan yaklaştığı- ki kendisi bunu "radikal yeniden-olumlama" olarak adlandırmıştır(2005) - Derrida'yı, iki ayrı başlıkta incelemektedir: 1. Dil 2. Felsefe. Aslında belirtmek gerekir ki, bu da sorunlu bir yaklaşımdır. Derrida, "dışarısı ile içerisi” üzerine kurduğu tartışmasında, kesin anlamsal ayrımları reddeder(Derrida, 1974). Buna göre, dil ile bilim, dil ile felsefe Derrida'nın en son değineceğimiz metodolojik yaklaşımına benzer olarak, Husserl ve Saussure metinlerinin okuması üzerinden yapılmış ve Derrida'nın aslında hiçbir koşulda tamamen anlaşılmasının mümkün olamayacağı ifade edilmiştir. Bizim ise bu çalışmada yapmak istediğimiz, daha kısa ve öz biçimde, yapısökümcülüğün dayandığı epistemolojik ve metodolojik zemin ile temel kavramları üzerinde durmak olacaktır.

\section{Pozitivizm, bilim ve dil}

Derrida öncelikli olarak, bilimin var oluşunda dilin önemini vurgular. Buna göre, bilimi belirleyen asıl unsur ve bilimin varlık alanı dildir. (1974) Modern bilim ise, dilin belli bir alanı olarak yazıma denk düşmektedir. Ancak Derrida'ya göre yazım, sözlü temele dayanır. Yani kadim öncülü olarak, söz, yazımı ve dolayısıyla bilimi oluşturan temel unsur, yazımın değişmez telos'udur. Bu nedenle, her ne kadar bilim felsefesi yazıma dayansa da, Derrida bilimin aslen kökeninde sözlü geleneklerin önemli olduğunu vurgular. Bu çerçevede Derrida güncele dair bir tartışmaya girmektedir: Bilim bu özünden ayrılmış ve belli bir tarihsellik çerçevesinde özünden kopuşa doğru sürüklenmiştir. Özellikle 18. yy.dan sonra bilimin giderek matematiksel olarak ele alınmaya başlandığını ve bunun aslında bilimin bir özbilinç kaybı yaşadığını öne sürmektedir. Bu açıdan, Derrida'nın eleştirilerinin temel odağı, tam da bizim sunmak istediğimiz epistemolojik tartışmayı ortaya çıkarmaktadır: Derrida'nın saldırılarının asıl hedefi pozitivist epistemolojidir. Buna göre, tarihsellik de yine yazım nedeniyle kurulmaktadır. $\mathrm{Bu}$ tarihselliğin ürünü olarak yaşadığımız toplum, bir kurgudan ibarettir. Bilim alanında da yine bu kurgu - Derrida'nın tabiriyle metafizik - kendisini muazzam miktarda bilginin arkasında gizlemektedir. Derrida'ya göre evrensel gerçeklik, metafizik bir ilkedir. Ve yine tüm batı düşünce geleneği ile modern toplum, bu metafizik kabule uygun olarak şekillenmektedir. (Derrida, 1978: 353)

Derrida'nın politik yanına daha sonra değineceğimizden, epistemoloji tartışmasına devam etmek faydalı olacaktır. Yazım tarihi dendiğinde, Derrida, tarihselliğin kökenine inmekte, ve bir tarih tanımı sunmaktadır. Buna göre tarih, arkeoloji değildir. Tarih, felsefeden dışsal olarak ele alınamayacak ve mutlaka tarih felsefesi veya felsefe tarihi ile ortaklaşacaktır. Pozitif bilimler bu bakışı baskılarlar. Bilimin tarihselliği ve dil temelinde kurulu yapısı, yadsınmadan, yani bilim tarih-üstü ve metin dışı bir gerçekliğe tahvil edilmeden, modern bilim işlev göremez. Derrida'ya göre, bunları yapmak, bilimsel araştırmalarına başlamak için bir zoruınluluktur. Derrida'ya göre analitik felsefe olarak tanımlanan felsefe biçimi, kurgusal bir ayrım üzerinden, metafizik olarak meydana gelmektedir (Derrida, 1988: 
133). Bu da linguistics(dil bilimi) ile fonoloji(ses bilimi) arasındaki ayrımdır. Burada çetrefilli bir durumdan söz etmek mümkündür: Buna göre, dil biliminin bilimselliği fonolojik kökenine bağlanırken, öte yandan fonolojinin bilimselliği de yine onun linguistic referanslarına dayandırılmaktadır. (Derrida, 1974) Burada aslen linguistics'in bilimsel olduğu öne sürülmektedir. Konuşma ve yazım arasındaki metafizik kabul, burada devreye girer. Fonoloji kendini görece bilim dışı bir alanda bulmaktadır. Bu açıdan, bilimsel dili linguistics belirlemektedir. Bu disiplin(linguistics) dilin en basit halini ve özünü eşit kılmaktadır: Mantık(logos) ve ses(phoné). Bu, pozitif aklın bastırdığ 1 soruya karşı ürettiği cevaptır aslında. Burada önemli olan, sesin, mantığın doğrudan bir ifadesi gibi yansıtılmasıdır. İşte kurgu da burada yatmaktadır. Derrida'ya göre, ses, mantığı, nesnel olarak ifade etmez. Aksine, dil, fonetik olarak kurulur (Derrida, 1973: 6) Bu açıdan, yazım, sesin yeniden ifadesidir. Bir diğer deyişle, yazım, "sembolün sembolüdür". Yine buna bağlı olarak, gramatolojinin "yazım nedir" sorusunun bir başka ifadesi aslında daha temelde "yazım nerede ve ne zaman başladı" olabilir. Yani, Derrida'nın savunduğu gramatolojik anlayış dili tarihselliğiyle incelediği gibi, yazımı ve bilimi de ses üzerine kurgular. Pozitivizmin başvurduğu yöntem ise bu metafiziği yani dilin nesnel olduğu ve sözün mantıktan yapısal olarak ayrıldığı ifadesini örtmek için teleolojik, araçsal ve "deliller"le bezeli tipolojik cevaplar sıralamak olmaktadır. Keza pozitif aklın basit tipolojik cevapları kolayca kurguya indirgenerek çürütülebilecektir. Bu kurguların kolayca çürütülebilmesi, kırılganlığ1 ile sunduğu muazzam bilgi ve veri yığını bir tezat oluşturmaktadır.

Burada Derrida'nın söylediği daha basit bir ifadeyle şudur: Pozitif bilimler, ürettiği birçok veri yığınına rağmen aslında metafizik bir temele oturmaktadır. Yani, modern toplum ve bilim başlı başına bir kurgunun eseridir. Bu açıdan dilin kodları, yani tüm ifadeler tarihseldir. Bu noktada, Nietzsche ve Frankfurt okulunda benzerini gördügümüz bir sonuca varmaktadır Derrida. Positions eserinde belirttiği şekliyle, Nietzsche, Platocu aklın batı düşünce ve toplumunu kurguladığını söylerken haklıdır (1981b: 37-41). Bu tarihsel logos, kendisini 18.yy sonrası Kanţ̧1 gelenekte yeniden üretmiştir. Ancak Derrida, Nietzsche'de ve eleştirel okulda, Platocu okulun politik saiklerinin ötesinde bir dil analizinin eksikliğine dikkat çekmektedir.

\section{Derrida'nın dil tartışması}

En son söylenecek şeyi en başta söyleyerek başlayalım, yukarıda başladığımız tartışmanın ima edeceği gibi, Derrida'ya göre hakikati ifade etmek için dil bugün yetersizdir. Dil, işte bu tarihsel kurgu tarafından şekillendirilmiştir. Bu nedenle dilin sorgulanması Derrida için felsefesinin temel amacıdır. Derrida, dili, felsefesinin temel sorunsalı yapmaktadır. Bir yanıyla da, toplumsal değişimi dilde değişime endekslemektedir (Derrida, 1994). ${ }^{2}$

2 Derrida, Marx'ın aslında mesajını olumlarken, hiçbir zaman tam olarak anlaşılmadığını ve dilde yıkım olmadan toplumsal yapıların sarsılamayacağını vurgular. 
Dildeki anlamlandırmalar, diğer kelimelerle mümkün olabilmektedir. Bunu ifade etmek için, "gösteren" ve "gösterilen" kavramlarını kullanmak gerekecektir. Dilde, gösterenden bağımsız bir gösterilen olamayacağı gibi, karşıtından bağımsız bir anlam da olamaz. Buna göre, her kavram, kıttıyla anlam kazanabilmektedir. Örnek olarak, madde/tin, iyi/kötü, özne/nesne, konuşma/yazı gibi. $\mathrm{Bu}$ açıdan, ses/söz/yazı ayrımı da yine bu logos yoluyla ortaya çıkmaktadır. Bu anlamlandırmaları mümkün kılan şey Derrida'nın sıkça kullandığı "différance” kavramıdır. Différance, Derrida'ya göre kelimelerin arasındaki anlamsal mesafe olabileceği gibi, kelimenin "hakiki" haliyle ya da özüyle arasındaki mesafe ya da tarihsel bir başka biçimiyle arasındaki mesafe olarak da tanımlanabilir. $\mathrm{Bu}$ olgunun tümüne, yani iki kavram veya anlam arasındaki farklılaşmanın gerçekleştiği durumun genelini ise differentiation(farklılaşma) olarak tanımlamaktadır. (Şekil 1)

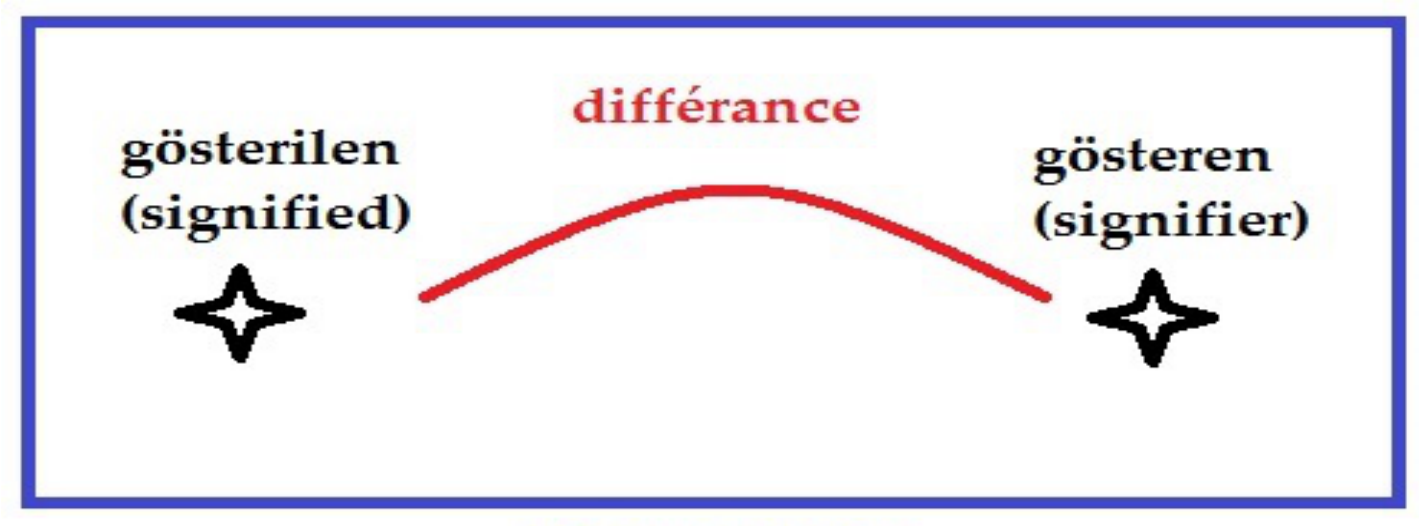

differentiation

Şekil 1: Derrida'da differentiation(farklılaşma) ve différance(fark) kavramları

Belirttiğimiz gibi, bir kavram mutlaka onu gösteren başka bir kavramla mesafelendirilerek oluşturulmaktadır. Bu açıdan her anlam mutlaka differantial(diferansiyel)'dir. Bu bağlamda gelinen nokta en önemli aksiyomlarımızdan birini ortaya çıkarmaktadır. Derrida'ya göre, hiçbir kavram dilden bağımsız düşünülemez. Burada, dilin, anlamsallığın hakiki formundan, yani özünden farklılaşması sonucu, çarpıtıcı bir işlevi bulunmaktadır. Derrida'nın savunduğu bu yaklaşım, daha önce bahsettiğimiz Platon'cu, aydınlanmacı dil geleneği tarafından oluşturulmuş metafizik evrensel hakikat

3 Burada Derrida'nın Marx'ın Essence olarak kullandığı̈ öze benzer bir ifade kullanarak temel Marxist ontolojiyle tekrar örtüştüğünü söylemek mümkün olmaktadır. Bu aslında, Derrida'nın Marxist olma savını destekler niteliktedir. Bir açıdan Derrida, Frankfurt okuluna benzer biçimde aslında Marxism'i pozitivizmden kurtarma çabasındadır. 
ilkesine bir saldırı anlamına gelmektedir. Buna göre, kavramlar gibi, onları barındıran hiçbir metin de bu çarpıtmadan kurtulamaz. Yani, bir metin, evrensel bir anlam taşımaz, birçok anlam barındırabilir. $\mathrm{Bu}$, bakanın kendi konumlandırdığı gösterenlere göre değişebilmektedir.

Derrida'nın işte "sökmeye" çalıştı̆̆ yapı burada kendini göstermektedir. Derrida'ya göre "normal" olarak tanımlanan standartlaştırıcı yaklaşım ve benzer şekilde iç/dış gibi basit diyalektik ayrımlar Platon'dan Kant'a, Hegel'e, Husserl'e, ve Saussure'e kadar birçok felsefecide bulunan bir mantık koduna(logos) dayanır. Modern toplumun kullandığı anlamlandırmaları bu logos belirler. Bu logosu sökmek yapısökümcülüğün temel işlevini oluşturur. Derrida, 'logocentrism' (mantıkmerkezcilik) dediği bu metafizik mantıkçılığa saldırır. (1988: 108-133)

\section{Metodolojik çerçeve ve aporia}

Derrida, eleştiri kavramını Kantçı anlamıyla kabul etmez. Kantçı kavramsallaştırmaya göre, eleştiri olumlanırken, eleştirel olanın dogmatik olmayan olduğu öne sürülmektedir. Derrida dilin kendisinin kaçınılmaz olarak dogmatik olduğunu söyledikten sonra, bu yüzden her eleştirinin de mutlaka dogmatik olduğunu ekler. Benzer şekilde, her argüman da dogmatiktir. Belirli kavramsal kabuller üzerine kurulduğu için, nesnel bir eleştiriden bahsetmek mümkün olamaz.

Bahsettiğimiz gibi, bir kavram evrensel bir anlam taşımaz ve mutlaka differential'dır. Dil ise öte yandan dogmatik ve standartlaştırıcı bir ilke üzerine kuruludur. Bu açıdan Derrida'ya göre bir metin tam olarak nesnel ve özdeş biçimde okunamaz. Yazım ve söz ancak belli bir noktaya kadar yapısından sökülerek okunabilir. Bu nokta aporia'dır. Aporia, zitlıklar üzerinden yapılan bir okumayı tanımlamaktadır. Bu okuma biçimi aporetik okumadır. (Currie, 2013: 111-3)

Derrida'nın eserlerinin büyük kısmı, yaptığı aporetik metin okumalarından oluşmaktadır. Derrida, gerek girdiği polemiklerde, gerekse akademik incelemelerinde bu stratejik yöntemi esas almaktadır. Aporetik okumanın birkaç aşamasından söz etmek mümkündür:

1. Öncelikle Derrida, metni teşkil eden önemli kavramları tespit ederek, metnin temel anlam çerçevesini sunar.

2. Bu anlam çerçevesi içindeki hiyerarşiyi ölçme. Üstün ve öncelikli olan logosu ortaya çıkarma. Derrida'ya göre modern toplumu oluşturan temel logos hiyerarşiye dayanmaktadır. Bunun bir örneğini dildeki yazım/söz tartışmasında görmüştük.

3. Bu logos'u değiştirerek başka bir açıdan da bir 'doğru'ya ulaşılabileceğini örnekleme. Bu örnekleme, doğruluk iddiası sunmanın aksine, bir doğrunun olamayacağını ispatlamak amaciyla yapılmaktadır.

Aporetik okuma yoluyla, anlamsallıkların nasıl kolayca çarpıtılabildiğini gösterirken, bir yanıyla da kavramsallığa saldırmaktadır Derrida. Burada, yapısökümcülük teorisini açıklarken de benzer bir yolu 
izlemektedir. Bu apothatic (apotetik) açıklama biçimidir. Temel olarak, ne olduğunu değil, ne olmadığını ifade ederek, teorisini negatif olarak tanımlama yoluna gider.

Buna göre, Derrida'nın teorik çerçevesi bir metod değildir. Bir metod olmadını söylemek bir yönüyle kendisini ciddi bir sorundan kurtarmak anlamına da gelmektedir. Çünkü ona göre, bir metod mekanik bir süreci tanımlar. Derrida, mekanik süreçlerin standartlaştırıcı ve dolayısıyla yapısalcı bir sonuca varacağını açıklar. Derrida, teorik çerçevesinin bir metodolojiden ziyade bir trace(iz) takip ettiğini savunur. Bu iz, kendisinin belirli bir logos izinden gittiğini değil, tam tersine her zaman açık seçik görünmeyen izleri (Derrida, 1976: 65) deşifre etmek için yapısökümcülüğü kullandığını ifade eder. Bir diğer deyişle, Derrida metodolojiyi değil, metodoloji karşıtlı̆̆ını metod edinmiştir.

Diğer yanıyla, bir analiz de değildir. Hiçbir metin, tümelliğinden bağımsız olarak incelenemez. Bu açıdan, Derrida analiz değil okuma yaptığını söylemektedir. Okuma yoluyla bozduğu metinlerin ortaya nesnel bir sonuç çıkaracağını savunmaz. Ona göre, hiçbir metnin kendi içinde anlamlı parçaları yoktur. Ancak metnin bütünü anlam barındırır. Benzer şekilde Derrida ikilemler ve dikotomiler üzerinden yapılan anlamsallaştırmaların bu logosa dayalı ve bir iz üzerinde durduğunu öne sürmektedir. Derrida, bir hayaletin ne tam anlamıyla var ne de yok olduğundan örnekle, fenomenolojinin de iç/dış, doğru/yanlış olarak tanımlanmayacağını öne sürer (1976: 281). Bu açıdan, fenomenoloji, asla yapılsalcı olmadığı gibi, kesinlikle post-yapısalcı da değildir. Kendisine göre yapısalcılık dışında bir felsefe düşünmek mümkün değildir. Bu da yine bizi en başta yaptığımız dil ve anlam tartışmasına götürmektedir. Dahası, Derida'ya göre bir kavramın bir anlamının olduğunu da söylemek mümkün olmayacaktır. Kavramlar sürekli olarak anlam değiştirirler. $\mathrm{Bu}$ nedenle zamanla olan ilişsisi bakımından Derrida "şu anın metafiziği”"ni yapmakla itham edilmiştir. Her kavram, sadece "şu an" olan, halihazırda olan ile sınırlanmış bir anlamsal çerçeveyi temsil etmektedir. Bu da yine Derrida'nın bilinemezcilik ilkesine bir boyut daha eklemektedir.

Tüm bunları genel olarak ifade etmek gerekirse, Derrida'nın kendi ifadesiyle, fenomenoloji "bir teori değildir, bir felsefe değildir, bir okul ya da tartışma değildir. Bu olandır, bugün toplumda, politikada, diplomaside, ekonomide, tarihte, vb. Yapısökümcülük durumdur. Bunu yalnızca doğru olduğunu düşündüğüm için değil, gösterebileceğim için de söylüyorum...” (Derrida, 1981a: 28-31)

\section{Sonuç olarak}

Derrida'ya göre yapısökümcülük açıklanamaz. Öncelikle, açıklama dil yoluyla yapılmak zorundadır ve bu da tam eleştirdiği şeye tekabül etmektedir. Ancak açıklanmaya çalışılabilir. Göstermek istediği de aslında budur. Derrida, politik çizginin dilde görebileceğimiz bu mantık izinden koparılmasıyla değişeceğine inanır. $\mathrm{Bu}$ açıdan, Adornogil yıkıcı entellektüelizm çabasına vakit ayırmaktadır. Hermeneutik/postmodern epistemolojiye ve kitasal(continental) felsefe okuluna dahil edebileceğimiz 
Derrida, fenomenolojiyi her türlü doğruluk iddiasını çürütmek için kullanır. Bu aynı zamanda en başta belirttiğimiz gibi, kendisini de çürütmek anlamına gelir. Teorik olarak, şüpheci(sceptic) okulun zirvesi olarak tanımlanabilecek olan yaklaşımı, kendi eleștirilerini, yani pozitivizm ve yapısalcılığa yönelttiği eleştirileri de bir yanıyla anlamsız kılmaktadır. Searle, Derrida'daki anlamsal belirsizlik ilkesinin, kendisine yöneltilen her eleştiriye, "yanlış anlaşılmış" diyerek kendisini de anlamsızlaştırdığını belirterek, "yapısalcılı̆̆ı "belirsizlik terörizmi" olarak tanımlar. (http://reason.com/archives/2000/02/01/reality-principles-an-intervie)

Derrida'nın teorisi ve okumaları, kendisinden sonra gelen birçok düşünürü etkilediği gibi, aynı zamanda hukuktan müziğe, görsel sanatlardan tarihe, sosyolojiye ve politikaya kadar birçok disiplini önemli biçimde etkilemiştir. İlginç olan bir nokta şudur ki, Derrida'nın hayatı süresince tartıştı̆̆ düşünürlerin çok azı kendisinin saldırdığı yapısalcı veya pozitivist düşünce okullarına dahil edilebilmektedir. (Sweetman, 1997) Anlam kalıplarına karşı eleştiri içeren birçok yaklaşıma öncülük etmiştir. "Öteki” üzerine yaptığı tartışmalarla, popüler kültür eleştirisine yönelmiş ve aynı zamanda ayrımcılık ve tektipleşme gibi toplumsal sorunlara dikkat çekmiştir. Bu açılardan tartışmasızdır ki, Derrida ve yapısökümcülük 20. yy'ın önemli bir düşünce alanı haline gelmiş ve yeni yüzyılda da felsefe dünyasını etkilemeye devam etmektedir. 


\section{KAYNAKÇA}

Currie, M. (2013) The Invention of Deconstruction, Palgrave Macmillan, New York.

Derrida, J. (1973) Speech and Phenomena, Northwestern University Press, Illinois.

Derrida, J. (1974) Of Grammatology, Hopkins University Press, 02.01.2014'te şu adresten ulaşılmıştır: <http://www.marxists.org/reference/subject/philosophy/works/fr/derrida.htm>

Derrida, J. (1976) Of Grammatology. Trans. Gayatri Chakravorty Spivak. Baltimore: Johns Hopkins University Press, Baltimore.

Derrida, J. (1978) 'Genesis' and 'structure' and Phenomenality, Writing and Difference, Routledge, London.

Derrida, J. (1981a) Interview with Julia Kristeva in Positions The University of Chicago Press.

Derrida, J. (1981b) Positions: (çev. Alan Bass), The University of Of Chicago Press, Chicago.

Derrida. J. (1988) Afterwords, Limited, Inc. Northwestern University Press, Illinois.

Derrida, J. (1994) Specters of Marx, the state of the debt, the Work of Mourning, \& the New International, translated by Peggy Kamuf, Routledge <http://www.marxists.org/reference/subject/philosophy/works/fr/derrida2.htm>

Interview with John Searle, Reason Magazine

< http://reason.com/archives/2000/02/01/reality-principles-an-intervie>

Kates, J. (2005) Esssential History, Jacques Derrida and the Development of Deconstruction, Introduction, Northwestern University Press, Illinois. 
Sweetman, B. (1997) The Deconstruction of Western Metaphysics: Derrida and Maritain on Identity, On Derrida, Postmodernism and Christian Philosophy, American Maritain Association Publications. 